\title{
PRODUÇÃO DE CLAMIDÓSPOROS DE Pochonia chlamydosporia EM DIFERENTES SUBSTRATOS
}

\author{
Production of chlamydospores of Pochonia chlamydosporia in different substrates
}

\author{
Rosangela Dallemole-Giaretta ${ }^{1}$, Leandro Grassi de Freitas ${ }^{2}$, Larissa de Brito Caixeta ${ }^{3}$, \\ Déborah Magalhães Xavier ${ }^{4}$, Silamar Ferraz ${ }^{2}$, Cléia de Fátima Silva Fabry ${ }^{5}$
}

\begin{abstract}
RESUMO
Clamidósporos são estruturas de sobrevivência do fungo nematófago Pochonia chlamydosporia. Objetivou-se, com este trabalho, avaliar diferentes substratos, teores de água e formas de inóculo para a produção in vitro de clamidósporos de $P$. chlamydosporia. Inicialmente, testaram-se os substratos grãos de milho triturado, grãos de arroz e casca de café e os tipos de inóculo meio líquido concentrado ou diluído (1:40) e discos de cultura, colonizados por P. chlamydosporia. Posteriormente, testou-se o substrato grãos de milho triturado suplementado ou não com caldo de batata com os inóculos do fungo nas formas de discos de micélio ou suspensão aquosa. As maiores produções de clamidósporos $\mathrm{g}^{-1}$ de substrato foram obtidas nos substratos grãos de milho triturado e casca de café, e as melhores formas de inóculo foram meio líquido diluído (1:40) e discos de micélio. A suplementação do substrato grãos de milho triturado com caldo de batata não aumentou a produção de clamidósporos do fungo e a melhor forma de inóculo do fungo foi a de discos de micélio. Além disso, testaram-se os substratos canjica, grãos de arroz, casca de café e fibra de coco, umedecidos com diferentes quantidades de água; o substrato casca de café umedecido por diferentes períodos; a casca de café enriquecida ou não com sacarose e farinha de arroz e o substrato grãos de arroz esterilizado no forno micro-ondas com diferentes quantidades de água. Apenas o substrato grãos de arroz, em todas as quantidades de água testadas, apresentou maior produção de clamidósporos. Não houve diferença na produção de clamidósporos no substrato casca de café umedecido por diferentes períodos e apenas quando a casca de café foi enriquecida com farinha de arroz, apresentou maior média de clamidósporos $\mathrm{g}^{-1}$ de substrato. Todos os tratamentos apresentaram grande produção de clamidósporos $\mathrm{g}^{-1}$ quando o substrato utilizado foi o de grãos de arroz tratados no forno de micro-ondas. O melhor meio de cultivo de $P$. chlamydosporia para a produção de clamidósporos foi o substrato contendo grãos de arroz.
\end{abstract}

Termos para indexação: Controle biológico, fungo nematófago, produção massal.

\section{ABSTRACT}

Chlamydospores are survival structures of the nematophagous fungus Pochonia chlamydosporia. The objective of this study was to evaluate different substrates, different contents of water and kinds of inoculum for the production of Pochonia chlamydosporia chlamydospores. The substrates evaluated were: milled maize, rice grains and coffee husk; all of them were inoculated with disks of culture, concentrated liquid media or diluted liquid media (1:40) colonized by P. chlamydosporia. Besides, the substrates milled maize, supplemented or not with potato broth, and inoculated with fungus disks or aqueous suspension were evaluated. Milled maize and coffee husk were the best substrates for chlamydospores production. The best inoculum kinds were disks of culture and diluted liquid media (1:40) colonized by P. chlamydosporia. The supplementation of milled maize with potato broth did not improve the production of chlamydospores, and the best inoculum form was disks of fungus. Moreover, it was also studied the substrates rice grains, coffee husk and coconut fibers with different rates of water; the substrate coffee husk moistened by different periods; the supplementation of coffee husk with rice flour or dextrose; and the substrate grains of rice sterilized in microwave oven with different rates of water. The substrate grains of rice, in all of the amounts of water tested showed increase in production of chlamydospores. There was no difference in the chlamydospores production of the coffee husk substrate, when moistened by different periods of time and only when it was supplemented with rice flour it showed higher mean of clamydospores per gram of substrate. All treatments evaluated showed higher production of chlamydospores in the substrate grains of rice treated in the microwave oven. The best substrate for the production of chlamydospores of $P$. chlamydosporia was the rice grains.

Index terms: Biological control, nematophagous fungi, mass production.

(Recebido em 23 de dezembro de 2009 e aprovado em 22 de setembro de 2010)

\footnotetext{
${ }^{1}$ Universidade Estadual do Centro-Oeste/UNICENTRO - Campus Cedeteg - Rua Camargo Varela de Sá - 03 - Vila Carli - $85040-080$ - Guarapuava, PR rodallemole@yahoo.com.br

2Universidade Federal de Viçosa/UFV - Departamento de Fitopatologia - Viçosa, MG

${ }^{3}$ Universidade Federal Rural de Pernambuco/UFRPE - Recife, PE

${ }^{4}$ Louisiana State University/ LSU - Baton Rouge, LA

${ }^{5}$ Universidade Federal dos Vales do Jequitinhonha e Mucuri/UFVJM - Laboratório de Fitopatologia - Diamantina, MG
} 


\section{INTRODUÇÃO}

O fungo nematófago Pochonia chamydosporia Zare \& Gams (sin. Verticillium chlamydosporium Goddard) é um parasita facultativo de ovos e fêmeas dos nematoides formadores de galhas (Meloidogyne Goeldi spp.) e de cistos (Heterodera avenae Wollenweber) amplamente distribuído em todo o mundo (Kerry et al., 1982).

Uma das vantagens desse antagonista que produz clamidósporos, estruturas de resistência e sobrevivência preferencialmente utilizadas como inóculo, podendo ser adicionados ao solo em suspensão aquosa sem fonte adicional de nutrientes. O inóculo de $P$. chlamydosporia, geralmente, é produzido nos meios de cultivo contendo grãos de milho, de trigo ou de cevada triturados (Kerry \& Bourne, 2002). Outros substratos, considerados resíduos culturais ou não, como folhas de milho, de nim, de berinjela, dentre outros, também já foram testados para a produção de inóculo do fungo (Bourne et al., 1999). Nesses materiais, a produção massal do fungo variou de 33 a $298 \times 10^{3}$ clamidósporos $\mathrm{g}^{-1}$ de substrato, considerada baixa quando comparada com o substrato grãos de cevada moída, com 1767 x $10^{3}$ clamidósporos $\mathrm{g}^{-1}$ de substrato. Em Cuba, esse antagonista é produzido em substrato grãos de arroz e, atualmente, nesse país, está em processo de registro um produto à base de $P$. chlamydosporia $\left(\mathrm{KlamiC}^{\circledR}\right)$ obtido nesse substrato, para o controle de espécies de Meloidogyne (Hernández \& Díaz, 2008).

No Brasil, ainda não há produtos comercializados à base de $P$. chlamydosporia para o controle de fitonematoides. Por isso há uma procura por fontes de nutrientes que proporcionem um bom crescimento micelial e produção de clamidósporos desse fungo para otimizar sua produção em escala comercial. Portanto, uma alternativa para a produção massal de micélio, conídios e principalmente, clamidósporos de $P$. chlamydosporia, é testar outros substratos sólidos de baixo custo que possam ser obtidos facilmente como os rejeitos agroindustriais, a exemplo da fibra de coco e da casca de café. A vantagem de se utilizar a fibra de coco é que, em muitas regiões, o coco verde causa transtorno ao serviço de limpeza pública pelo volume e pela dificuldade de sua decomposição, produzindo uma fibra que pode ser utilizada como substrato (Carrijo et al., 2002). Além disso, como o estado de Minas Gerais é o maior produtor nacional de café, com $44,8 \%$ da produção brasileira (Companhia Nacional de Abastecimento - Conab, 2007), a casca de café é um resíduo da agroindústria brasileira que pode ser testado como substrato para a produção de clamidósporos de $P$. chlamydosporia. Independentemente do substrato utilizado, é importante maximizar a produção massal de clamidósporos de P. chlamydosporia pelo ajuste de metodologias no processo de produção do fungo.

Objetivou-se, com este trabalho, avaliar diferentes substratos, teores de água e formas de inóculo para a produção in vitro de clamidósporos de $P$. chlamydosporia.

\section{MATERIAL E MÉTODOS}

O isolado de $P$. chlamydosporia var. chlamydosporia, Pc-10, utilizado neste trabalho pertence à coleção de fungos nematófagos do Laboratório de Controle Biológico de Fitonematoides da Universidade Federal de Viçosa. Foram conduzidos seis experimentos, para avaliar a produção de clamidósporos do fungo em diferentes meios de cultivo.

Experimento I: Produção de clamidósporos de $P$. chlamydosporia nos substratos contendo grãos de milho triturado (canjica), grãos de arroz e casca de café, inoculados com discos de cultura ou meio líquido contendo o fungo.

O fungo, $P$. chlamydosporia, previamente cultivado no meio 'Corn Meal Agar' (CMA), com idade de uma semana, foi repicado para placas de Petri, contendo meio de cultura 'Batata-Dextrose-Ágar (BDA) ou para frascos tipo Erlenmayer de $250 \mathrm{~mL}$ de capacidade, contendo $150 \mathrm{~mL}$ de meio líquido (30 $\mathrm{g}^{-1} \mathrm{~L}$ de sacarose e $20 \mathrm{~g}^{-1} \mathrm{~L}$ de extrato de levedura), mantidos em sob agitação de $170 \mathrm{rpm}$. Ambos os inóculos foram incubados a $25 \pm 1^{\circ} \mathrm{C}$, no escuro, por 21 dias.

Em sacos de polipropileno autoclaváveis $(38 \mathrm{~cm}$ de largura $\times 45 \mathrm{~cm}$ de comprimento), foram colocados separadamente $400 \mathrm{~g} \mathrm{saco}^{-1}$ dos substratos grãos de milho triturado (canjica) ou grãos de arroz e $160 \mathrm{~mL}$ de água. $\mathrm{O}$ substrato casca de café foi fervido por 3 horas e colocado em uma peneira para retirada do excesso de água. A seguir, foram colocados $200 \mathrm{~g}$ desse substrato $\mathrm{saco}^{-1}$. Os sacos foram fechados na ponta com o auxílio de uma borracha e autoclavados a $120^{\circ} \mathrm{C}$ e 1 atm por 30 minutos. Em câmara de fluxo laminar, em cada saco contendo os substratos, foram colocados separadamente 5 discos de micélio de $7 \mathrm{~mm}$ ou $20 \mathrm{~mL}$ do meio líquido concentrado ou diluído, contendo $P$. chlamydosporia. A diluição do meio líquido foi feita na proporção de 1:40 em água destilada e esterilizada. A temperatura e o período de incubação foram as mesmas para o crescimento do inóculo fúngico. $\mathrm{O}$ experimento foi montado em delineamento inteiramente casualizado, em arranjo fatorial $3 \times 3$ (tipos de inóculo do fungo x diferentes substratos), com seis repetições por tratamento.

Para a estimativa do número de clamidósporos por gramas de substrato, pesou-se previamente cada repetição de cada tratamento. Posteriormente, adicionou-se $1 \mathrm{~L}$ de água em cada saco contendo o substrato crescido pelo 
fungo. Agitou-se até obter uma solução homogênea e uma alíquota de aproximadamente $40 \mu$ foi retirada para a contagem dos clamidósporos em câmera de Neubauer. Foram realizadas seis leituras por repetição.

Experimento II: Produção de clamidósporos de $P$. chlamydosporia em substrato contendo grãos de milho triturado (canjica) enriquecido ou não com caldo de batata e fibra de coco e inoculados com discos de micélio ou suspensão aquosa contendo o fungo.

Em sacos de polipropileno autoclaváveis $(38 \mathrm{~cm}$ de largura x $45 \mathrm{~cm}$ de comprimento), foram colocados $400 \mathrm{~g}$ do substrato grãos de milho triturado e $150 \mathrm{~mL}$ de água destilada ou caldo de batata obtido pela cocção de $200 \mathrm{~g}$ de batata em um litro de água de torneira por aproximadamente 20 minutos. Os procedimentos metodológicos para a montagem e condução do experimento foram similares ao experimento I. No entanto, no experimento II, foram colocados 7 discos de micélio de $5 \mathrm{~mm}$ de diâmetro por saco de substrato. $\mathrm{O}$ inóculo em meio líquido de $P$. chlamydosporia foi obtido pela agitação com água destilada e autoclavada do substrato contendo grãos de milho triturado, previamente colonizado por 21 dias pelo fungo. O experimento foi montado em delineamento inteiramente casualizado, em arranjo fatorial 2 x 2 (tipos de inóculo do fungo x suplementação do substrato), com seis repetições por tratamento.

Além desse experimento, montou-se outro ensaio, no qual se testou apenas o substrato fibra de coco tipo 8 e 11 , sendo que para cada $100 \mathrm{~g}$ de substrato colocaramse $170 \mathrm{~mL}$ de água e inoculou-se apenas com as mesmas quantidade de discos de micélio do fungo.

Para as avaliações quanto ao número de clamidósporos, adaptou-se a metodologia descrita por De Leij et al. (1991), quantificando-se o número de clamidósporos $\mathrm{g}^{-1}$ de substrato. Foram coletadas três amostras por repetição e realizadas duas leituras por amostra.

Experimento III: Produção de clamidósporos de $P$. chlamydosporia em diferentes substratos e volumes de água.

Em sacos de polipropileno autoclaváveis $(38 \mathrm{~cm}$ de largura x $45 \mathrm{~cm}$ de comprimento), foram colocados separadamente $100 \mathrm{~g}$ dos substratos milho triturado (canjiquinha), grãos de arroz, casca de café ou fibra de coco e água nas quantidades de 40, 50, $60 \mathrm{ou} 70 \mathrm{~mL} \mathrm{saco}^{-1}$, respectivamente. A esterilização dos substratos, a montagem e a avaliação do número de clamidósporos foram similares ao experimento 2. Porém, no experimento III, foram injetados $10 \mathrm{~mL}$ de suspensão fúngica de $P$. chlamydosporia, Pc-10, previamente multiplicado em meio líquido (idem experimento I).

Para as avaliações quanto ao número de clamidósporos, adaptou-se a metodologia descrita por De Leij et al. (1991). Um grama do substrato colonizado pelo fungo foi colocado em um frasco tipo Erlenmayer de $250 \mathrm{~mL}$ de capacidade, contendo $40 \mathrm{~mL}$ de solução de Tween ${ }^{\circledR}$ a $0,05 \%$, e agitou-se cada amostra por 3 minutos, quantificando-se o número de clamidósporos $\mathrm{g}^{-1} \mathrm{de}$ substrato em câmera de Neubauer. Foram coletadas três amostras por repetição e realizadas duas leituras por amostra.

$\mathrm{O}$ experimento foi montado em delineamento inteiramente casualizado, em arranjo fatorial 4 x 4 (tipos de substrato x quantidade de água), com seis repetições por tratamento.

Experimento IV: Produção de clamidósporos de $P$. chlamydosporia em substrato contendo casca de café umedecida com água por diferentes períodos, antes da autoclavagem.

O substrato casca de café foi deixado de molho em água por 10, 20, 30, 40, 50, 60 minutos ou 3 horas antes da autoclavagem. Posteriormente, cada tratamento foi espalhado individualmente sobre peneiras e deixado por 20 horas para escorrer o excesso de água. Em seguida, foram colocados $300 \mathrm{~g}$ de substrato em sacos de polipropileno e autoclavados a $120^{\circ} \mathrm{C}$ e $1 \mathrm{~atm}$, por 30 minutos. Posteriormente, foram injetados $20 \mathrm{~mL}$ de inóculo do fungo, previamente multiplicado em meio líquido (idem experimento I). A condução do experimento e as avaliações do número de clamidósporos foram feitas conforme experimento III. O delineamento estatístico foi o inteiramente casualizado, com sete repetições por tratamento.

Experimento V: Produção de clamidósporos de $P$. chlamydosporia em substrato contendo casca de café enriquecida com sacarose ou farinha de arroz.

Em baldes de plástico de $10 \mathrm{~L}$ de capacidade, foram colocados separadamente $1 \mathrm{~kg}$ do substrato casca de café, $4 \mathrm{~L}$ de água e açúcar cristal (Alto Alegre ${ }^{\circledR}: 99,6 \%$ de sacarose) ou farinha de arroz, obtida pela moagem de grãos de arroz com casca (4 colheres de sopa $\mathrm{kg}^{-1}$ de substrato). No tratamento testemunha, apenas água foi adicionada à casca de café. O substrato permaneceu de molho por 15 minutos e, em seguida, foi colocado sobre peneiras, permanecendo por 16 horas para escorrer o excesso de água. Posteriormente, foram colocados $100 \mathrm{~g}$ de substrato por saco. A montagem, condução e avaliação foram semelhantes àquelas do experimento IV, exceto que neste ensaio foram injetados $10 \mathrm{~mL}$ da suspensão do fungo por saco de substrato. 
Experimento VI: Produção de clamidósporos de $P$. chlamydosporia em substrato grãos de arroz com diferentes quantidades de água e esterilizado em forno micro-ondas ou na autoclave.

Para a esterilização do substrato em forno microondas, marca Panasonic (Modelo NN72098H), foram colocados separadamente em sacos de polipropileno autoclaváveis $100 \mathrm{~g}$ do substrato grãos de arroz triturado e água nas quantidades de 60, 70, 80, $90 \mathrm{ou} 100 \mathrm{~mL} \mathrm{saco}{ }^{-1}$. O substrato permaneceu de molho por 1 hora. A seguir, o substrato foi espalhado manualmente de forma a ficar uma camada fina nos sacos. Em seguida, foi realizado o tratamento do substrato em forno de micro-ondas na potência máxima por 3 minutos, esterilizando um saco por vez. No final do tratamento, cada saco foi fechado na ponta com o auxílio de uma borracha. O substrato que foi autoclavado foi deixado de molho por 30 minutos, com uma quantidade de água a cobrir o substrato. Posteriormente, escorreu-se o excesso de água, colocaramse $100 \mathrm{~g}$ de substrato $\mathrm{saco}^{-1} \mathrm{e}$, em seguida, foram autoclavados a $120^{\circ} \mathrm{C}$ e $1 \mathrm{~atm}$, por 30 minutos.
A montagem, condução e avaliação foram semelhantes àquelas do experimento $\mathrm{V}$. $\mathrm{O}$ experimento foi montado em delineamento inteiramente casualizado com seis repetições por tratamento. Os resultados obtidos de todos os experimentos foram submetidos à análise de variância pelo teste $\mathrm{F}$ e, quando significativos, as médias foram comparadas pelos testes Tukey ou Dunnet a $5 \%$ de probabilidade. No experimento I, para análise estatística, os dados dos números de clamidósporos foram transformados em $\sqrt{x}$.

\section{RESULTADOS E DISCUSSÃO}

Nos experimentos I, II e III, respectivamente, não houve interação significativa entre tipo de substrato e inóculo de P. chlamydosporia; tipo de inóculo do fungo e suplementação do substrato; e tipo de substratos e quantidade de água, na produção de clamidósporos do fungo (Tabelas 1, 2 e 3). Observou-se apenas o efeito significativo ou não na produção de clamidósporos de $P$. chlamydosporia em cada tratamento testado.

A necessidade de se realizarem estudos visando à maximização da produção de inóculo na forma de

Tabela 1 - Produção de clamidósporos em diferentes substratos e fontes de inóculo de Pochonia chlamydosporia.

\begin{tabular}{|c|c|c|c|c|}
\hline \multirow[t]{2}{*}{ Inóculo de $P$. chlamydosporia } & \multicolumn{4}{|c|}{ Substrato } \\
\hline & Grãos de milho (Canjica) & Grãos de Arroz & Casca de café & Médias \\
\hline & \multicolumn{4}{|c|}{ Clamidósporos $\mathrm{g}^{-1}$ de substrato } \\
\hline Meio líquido concentrado & $1,9 \times 10^{5}$ & $1,7 \times 10^{4}$ & $2,4 \times 10^{5}$ & $1,5 \times 10^{5} \mathrm{~b}$ \\
\hline Meio liquido diluído (1:40) & $2,6 \times 10^{5}$ & $1,8 \times 10^{5}$ & $2,7 \times 10^{5}$ & $2,4 \times 10^{5} \mathrm{a}$ \\
\hline Discos de micélio & $1,5 \times 10^{5}$ & $1,2 \times 10^{5}$ & $3,7 \times 10^{5}$ & $2,1 \times 10^{5} \mathrm{ab}$ \\
\hline Médias & $2,0 \times 10^{5} \mathrm{a}$ & $1,1 \times 10^{5} \mathrm{~b}$ & $2,9 \times 10^{5} \mathrm{a}$ & \\
\hline $\mathrm{CV}(\%)$ & & & 41,73 & \\
\hline
\end{tabular}

Os valores apresentados são os dados originais. Média de seis repetições. Médias seguidas pela mesma letra não diferem entre si pelo Teste de Tukey a $5 \%$ de probabilidade $(P=0,036)$.

Tabela 2 - Produção de clamidósporos em substrato grãos de milho triturado enriquecido ou não com caldo de batata e diferentes fontes de inóculo de Pochonia chlamydosporia.

\begin{tabular}{|c|c|c|c|}
\hline \multirow{2}{*}{ Inóculo de $P$. chlamydosporia } & \multicolumn{3}{|c|}{ Substrato } \\
\hline & $\begin{array}{l}\text { Grãos de milho } \\
\text { (Canjica) }\end{array}$ & $\begin{array}{c}\text { Grãos de milho (Canjica) } \\
+ \text { caldo de batata }\end{array}$ & Médias \\
\hline & \multicolumn{3}{|c|}{ Clamidósporos $\mathrm{g}^{-1}$ de substrato } \\
\hline Disco de micélio & $9,4 \times 10^{4}$ & $6,7 \times 10^{4}$ & $8,0 \times 10^{4} \mathrm{a}$ \\
\hline Suspensão aquosa & $4,5 \times 10^{4}$ & $4,2 \times 10^{4}$ & $4,3 \times 10^{4} \mathrm{~b}$ \\
\hline Médias & $6,9 \times 10^{4 \mathrm{~ns}}$ & $5,4 \times 10^{4 \mathrm{~ns}}$ & \\
\hline $\mathrm{CV}(\%)$ & \multicolumn{3}{|c|}{51,75} \\
\hline
\end{tabular}

Médias obtidas de seis repetições. Médias seguidas por letras diferentes diferem entre si pelo teste de Tukey a 5\% de probabilidade $(P=0,01) .{ }^{\text {ns }}$ Não significativo pelo teste $\mathrm{F}$, a $5 \%$ de probabilidade $(P=0,26)$. 
clamidósporos, de $P$. chlamydosporia, deve-se ao fato desse fungo ser um dos agentes de controle biológico mais estudados por apresentar grande potencial no controle do nematoide das galhas e de cistos (Crump \& Irving, 1992; Lopes et al., 2007). Esse antagonista produz três tipos de inóculo, micélio, conídio e clamidósporos (Stirling et al., 1998; Kerry \& Bourne, 2002). Os clamidósporos são o inóculo mais efetivo para o estabelecimento do fungo no solo e na rizosfera, por não necessitar de fonte adicional de nutrientes. A produção dos clamidósporos usualmente é obtida nos substratos grãos de milho, de trigo ou de cevada triturados, em pequenas quantidades, visando apenas ao inóculo do fungo para fins experimentais (Kerry \& Bourne, 2002). Portanto, visando ao desenvolvimento de produto comercial à base de $P$. chlamydosporia para o controle de fitonematoides, são necessários estudos para maximizar e padronizar a produção de inóculo desse antagonista.

No experimento I, as maiores médias de produções de clamidósporos foram obtidas nos substratos grãos de milho triturado e casca de café com valores de $2,0 \times 10^{5}$ e $2,9 \times 10^{5} \mathrm{~g}^{-1}$ de substrato, respectivamente. O inóculo de $P$. chlamydosporia que proporcionou maior média de produção de clamidósporos foi o meio líquido diluído, seguido de discos de micélio e meio líquido concentrado, apresentando valores de $2,4 \times 10^{5} ; 2,1 \times 10^{5} \mathrm{e} 1,5 \times 10^{5} \mathrm{~g}^{-1} \mathrm{de}$ substrato (Tabela 1), respectivamente.

No experimento II, a produção média de clamidósporos no substrato grãos de milho enriquecido com caldo de batata não diferiu estatisticamente, quando comparada com esse mesmo tipo de substrato, umedecido apenas com água (Tabela 2). No entanto, houve diferença significativa no número de clamidósporos quando se analisou o tipo de inóculo de P. chlamydosporia. Maior produção média de clamidósporos foi obtida quando o inóculo do fungo foi colocado no substrato em forma de discos de micélio do que em suspensão aquosa, obtendose valores de $8,0 \times 10^{4}$ e 4,3 x $10^{4}$ clamidósporos $\mathrm{g}^{-1} \mathrm{de}$ substrato, respectivamente. No substrato fibra de coco, não houve crescimento e produção de clamidósporos de $P$. chlamydosporia (dados não apresentados).

No experimento III, houve diferença significativa quanto à produção média de clamidósporos apenas entre os diferentes substratos testados (Tabela 3). A maior produção foi obtida no meio de cultivo grãos de arroz com $1,5 \times 10^{6}$ clamidósporos $\mathrm{g}^{-1}$ de substrato, seguido do substrato grãos de milho triturado e casca de café, com $8,6 \times 10^{5}$ e 8,5 x $10^{4}$ clamidósporos $\mathrm{g}^{-1}$ de substrato, respectivamente. No substrato fibra de coco não houve o desenvolvimento do fungo (dados não apresentados).

A ausência de clamidósporos no substrato fibra de coco, em ambos os ensaios, deve ter ocorrido devido à falta de ajuste da umidade ideal para a produção desse tipo de inóculo de $P$. chlamydosporia (Kerry \& Bourne, 2002). Tal fato é sugerido, pois, Coutinho (2008), ao utilizar esse mesmo substrato, relata que obteve a quantidade de $7,5 \times 10^{3}$ clamidósporos $\mathrm{g}^{-1}$ de fibra de coco. No experimento II, foi utilizada a quantidade de $170 \mathrm{~mL}$ de água por $100 \mathrm{~g}$ de substrato, possivelmente, alta para o estabelecimento e produção de clamidósporos do fungo nesse tipo de substrato. Já no experimento III, a maior quantidade de água testada, $70 \mathrm{~mL}$ de água em $100 \mathrm{~g}$ de substrato, não foi suficiente para promover o umedecimento homogêneo do substrato, afetando assim a colonização do fungo no meio

Tabela 3 - Produção de clamidósporos de $P$. chlamydosporia em diferentes substratos umedecidos com diferentes quantidades de água antes da autoclavagem.

\begin{tabular}{ccccc}
\hline $\begin{array}{c}\text { Quantidade de água } \\
\left(\mathrm{mL} .100 \mathrm{~g}^{-1} \text { de substrato }\right)\end{array}$ & \multicolumn{4}{c}{ Substrato } \\
& Grãos de milho (Canjica) & Grãos de Arroz & Casca de café & Médias \\
\hline \multicolumn{5}{c}{ Clamidósporos g $\mathrm{g}^{-1}$ de substrato } \\
\hline 50 & $8,1 \times 10^{5}$ & $2,2 \times 10^{6}$ & $2,8 \times 10^{3}$ & $1,0 \times 10^{6 \mathrm{~ns}}$ \\
60 & $9,4 \times 10^{5}$ & $1,4 \times 10^{6}$ & $3,6 \times 10^{4}$ & $7,9 \times 10^{5 \mathrm{~ns}}$ \\
70 & $1,0 \times 10^{6}$ & $1,3 \times 10^{6}$ & $6,1 \times 10^{4}$ & $7,9 \times 10^{5 \mathrm{~ns}}$ \\
Médias & $6,8 \times 10^{5}$ & $1,1 \times 10^{6}$ & $2,4 \times 10^{5}$ & $6,7 \times 10^{5 \mathrm{~ns}}$ \\
\hline CV $(\%)$ & $8,6 \times 10^{5} \mathrm{~b}$ & $1,5 \times 10^{6} \mathrm{a}$ & $8,5 \times 10^{4} \mathrm{c}$ & \\
\hline
\end{tabular}

Médias obtidas de seis repetições. Médias seguidas por letras diferentes diferem entre si pelo teste de Tukey a 5\% de probabilidade $(P=0,01) .{ }^{\text {ns }}$ Não significativo pelo teste $\mathrm{F}$, a $5 \%$ de probabilidade $(P=0,52)$. 
de cultivo. Além disso, sugere-se que a baixa colonização da fibra de coco pode estar ligada à pequena quantidade de hemicelulose ( 3 a $12 \%$ ) presente na fibra de coco (Noguera et al., 2000), que é a fração prontamente atacada pelos microrganismos.

Teores mais baixos de umidade também podem ter afetado a produção de clamidósporos no substrato grãos de milho triturado suplementado ou não com caldo de batata e casca de café (Tabelas 2 e 3). No experimento II, foram colocados apenas $37,5 \mathrm{~mL}$ de água ou caldo de batata em $100 \mathrm{~g}$ de substrato grãos de milho triturado, considerado baixo quando comparado com o experimento III, pois, a adição de $40 \mathrm{~mL}$ de água em 100 gramas, nesse mesmo tipo de substrato ou grãos de arroz, já foi suficiente para promover uma grande produção de clamidósporos de $P$. chlamydosporia. No entanto, para o substrato casca de café, esta quantidade de água apresentou a menor produção média de clamidóporos do fungo. Tal fato ocorreu porque essa quantidade de água não foi suficiente para promover uma uniformização na umidade desse substrato, afetando, consequentemente, o crescimento do fungo. Isso se deve devido características físicas e químicas da casca de café, quando comparada com os outros tipos de substratos testados neste experimento.

Outro fator que possivelmente afetou a produção dos clamidósporos do fungo no substrato casca de café, no experimento III, deve-se ao fato de esse substrato não ter sido deixado de molho como nos experimentos I e IV. No experimento IV, a produção média de clamidósporos por grama de substrato foi de $1,6 \times 10^{6} ; 1,8 \times 10^{6} ; 1,6 \times 10^{6}$; $1,5 \times 10^{6} ; 1,4 \times 10^{6} ; 1,5 \times 10^{6}$ e $1,4 \times 10^{6}$ do menor para o maior período de umedecimento do substrato, respectivamente, não constatando, portanto, diferenças significativas na produção média de clamidósporos de $P$. chlamydosporia no substrato casca de café umedecido em água por diferentes períodos.

A imersão da casca de café em água, antes da autoclavagem, pode ter removido grande quantidade de tanino e/ou de outros compostos tóxicos presentes no substrato que podem ter sido prejudicial ao crescimento de $P$. chlamydosporia. O efeito do tanino e da cafeína sobre o crescimento de cogumelos comestíveis, a exemplo do Pleurotus ostreatus (Jacq.) P. Kumm, já foi comprovado em outros estudos (Fan et al., 2003, 2006). No entanto, a porcentagem de constituintes químicos presentes na casca de café pode variar dependendo do modo e da eficácia do processamento do café, da variedade e do cultivo do cafeeiro (Pandey et al., 2000). Isso faz com que esse substrato não seja homogêneo podendo, portanto, afetar a produção de clamidósporos de $P$. chlamydosporia. Tal hipótese deve ter ocorrido no experimento $\mathrm{V}$, pois a casca de café passou pelos mesmos procedimentos metodológicos que o experimento IV e, mesmo enriquecida com sacarose e farinha de arroz, produziu menos clamidósporos do que o experimento IV. As produções médias de clamidósporos por grama de substrato no experimento $\mathrm{V}$, foram de $2,4 \times 10^{5}$ no tratamento contendo casca de café + farinha de arroz, diferindo da testemunha (apenas casca de café), que apresentou um valor médio de $9,2 \times 10^{4}$, e o tratamento contendo casca de café + sacarose, apresentou um valor médio de $1,1 \times 10^{5}$ de clamidósporo $\mathrm{g}^{-1}$ de substrato, não havendo diferenças significativas do controle.

Contudo, neste experimento, a suplementação do substrato com farinha de arroz aumentou a produção de clamidósporos, o que não ocorreu no experimento II, quando a canjica foi enriquecida com caldo de batata. Em estudos realizados por Donini et al. (2005) e Marino et al. (2008) com os substratos capim-elefante suplementado com dextrose ou serragem da casca de coco mais farelos de trigo e/ou de arroz também constaram que a suplementação dos meios de cultivo aumentou o crescimento do fungo Pleurotus spp. Portanto, dependendo do substrato utilizado, a adição de outras fontes de carbono pode ser uma alternativa viável para a produção de clamidósporos de $P$. chlamydosporia como observado neste estudo ao suplementar a casca de café com a farinha de arroz.

Neste ensaio também foi comprovado que o tipo de inóculo de $P$. chlamydosporia pode influenciar a produção de clamidósporos. A combinação da fermentação em estado líquido e sólido é um método rotineiro para o crescimento de $P$. chlamydosporia (De Leij et al., 1991; Pérez-Rodríguez et al., 2007). Além disso, este fungo também pode ser produzido somente em estado sólido (Bourne et al., 1999). Pela análise dos resultados de produção de clamidósporos, foi comprovado que a inoculação com discos de micélio resultou em grande produção de clamidósporos tanto no experimento I como no II (Tabelas 1 e 2). A desvantagem da utilização desse tipo de inóculo é que, em escala comercial, a inoculação é mais trabalhosa e demanda mais tempo. A maior produção de clamidósporos de $P$. chlamydosporia na fermentação em estado líquido e sólido foi obtida quando o fungo foi produzido em meio líquido, possivelmente, por esse tipo de inóculo possibilitar um crescimento mais rápido e homogêneo do antagonista no substrato.

No experimento VI, todos os tratamentos testados apresentaram grande produção de clamidósporos no substrato contendo grãos de arroz, quando comparados com o tratamento testemunha (Tabela 4). Os valores obtidos foram de $1,75 \times 10^{6}$ a 2,55 x $10^{6} \mathrm{~g}^{-1}$ de substrato. As menores produções de clamidósporos de $P$. chlamydosporia foram 
Tabela 4 - Produção de clamidósporos de $P$. chlamydosporia em substrato grãos de arroz esterilizado na autoclave ou no forno de micro-ondas.

\begin{tabular}{|c|c|}
\hline Tratamentos & Clamidósporos $\mathrm{g}^{-1}$ de substrato $\mathrm{X} 10^{6}$ \\
\hline Substrato esterilizado na autoclave (Testemunha) & 2,73 \\
\hline Substrato esterilizado no FMIC (60 mL de água) & 2,48 \\
\hline Substrato esterilizado no FMIC (70 mL de água) & 2,55 \\
\hline Substrato esterilizado no FMIC ( $80 \mathrm{~mL}$ de água) & $1,75 *$ \\
\hline Substrato esterilizado no FMIC (90 mL de água) & $1,85 *$ \\
\hline Substrato esterilizado no FMIC (100 mL de água) & 2,02 \\
\hline $\mathrm{CV}(\%)$ & 24,28 \\
\hline
\end{tabular}

Médias de seis repetições. *Médias que diferem da testemunha $(P=0,01)$ no teste de médias de Dunnett. FMIC $=$ forno de micro-ondas.

observadas nos tratamentos em que se utilizaram as quantidades de 80 ou $90 \mathrm{~mL}$ de água em $100 \mathrm{~g}$ de substrato. No entanto, essas médias de clamidósporos são consideradas altas, quando comparadas com os valores obtidos nos tratamentos do experimento III.

Portanto, como, neste estudo, se constatou que até $100 \mathrm{~mL}$ de água em $100 \mathrm{~g}$ de substrato contendo grãos de arroz não afetaram a produção de clamidósporos do fungo, recomenda-se utilizar entre 70 e $80 \mathrm{~mL}$ de água por $100 \mathrm{~g}$ desse substrato quando optar por esse método de esterilização, pois estas quantidades permitem um melhor manuseio e preparo do substrato nos sacos plásticos para a esterilização e cozimento dos grãos de arroz. Além disso, neste estudo, constatou-se que a esterilização do substrato contendo grãos de arroz por meio do forno tipo micro-ondas é eficiente e rápida. Isso permite que se economize tempo no preparo de substratos para realizar estes tipos de estudos, visando à maximização da produção de clamidósporos de $P$. chlamydosporia. $\mathrm{O}$ único inconveniente para a utilização de micro-ondas para a produção massal do fungo é o tamanho do aparelho, que tem que ser especial e de fluxo contínuo, já disponível no Brasil para uso industrial.

\section{CONCLUSÕES}

Foi possível concluir que o melhor meio de cultivo de $P$. chlamydosporia para a produção de clamidósporos foi o substrato contendo grãos de arroz em todas as quantidades de umidade testadas e independentemente do tipo de esterilização utilizada.

\section{AGRADECIMENTOS}

Os autores agradecem ao Conselho Nacional de Desenvolvimento Científico e Tecnológico $(\mathrm{CNPq})$, à
Fundação de Amparo à Pesquisa do Estado de Minas Gerais (FAPEMIG) e à Coordenação de Aperfeiçoamento de Pessoal de Nível Superior (Capes), pelo apoio financeiro.

\section{REFERÊNCIAS BIBLIOGRÁFICAS}

BOURNE, J.M.; KERRY, B.R.; GALLOWAY, J.; SMITH, C.; MARCHESE, G. Evaluation of application techniques and materials for the production of Verticillium chlamydosporium in experiments to control root-knot nematodes in glasshouse and field trials. International Journal of Nematology, College Park, v.9, n.2, p.153-162, 1999.

CARRIJO, O.A.; LIZ, R.S. de; MAKISHIMA, N. Fibra da casca do coco verde como substrato agrícola. Horticultura Brasileira, Brasília, v.20, n.4, p.533-535, 2002.

\section{COMPANHIA NACIONAL DEABASTECIMENTO.}

Secretaria da Produção e Comercialização. Safra brasileira de café estimada 2007/2008. Brasília, 2006. Disponível em: <http://Www.conab.gov.brì Acesso em: 8 jul. 2007.

\section{COUTINHO, M.M. Utilização de Pochonia chlamydosporia e farinha de semente de mamão (Carica} papaya L.) para o controle de Meloidogyne javanica. 2008. 63p. Dissertação (Mestrado em Fitopatologia)Universidade Federal de Viçosa, Viçosa, 2008.

CRUMP, D.H.; IRVING, F. Selection of isolates and methods of culturing Verticillium chlamydosporium and its efficacy as a biological control agent of beet and potato cyst nematodes. Nematologica, Leiden, v.38, p.367-374, 1992. 
DE LEIJ, F.A.A.M.; KERRY, B.R. The nematophagous fungus Verticillium chlamydosporium as a potential biological control agent for Meloidogyne arenaria.

Revue de Nématologie, Paris, v.14, n.1, p.157-164, 1991.

DONINI, L.P.; BERNARDI, E.; MINOTTO, E.;

NASCIMENTO, J.S. Desenvolvimento in vitro de Pleurotus spp. sob a influência de diferentes substratos e dextrose. Arquivos do Instituto Biológico, São Paulo, v.72, n.3, p.331-338, 2005.

FAN, L.; SOCCOL, A.T.; PANDEY, A.; SOCCOL, C.R. Cultivation of Pleurotus mushrooms on Brazilian coffee husk and effects of caffeine and tannic acid. Micologia Aplicada International, v.15, n.1, p.15-21, 2003.

FAN, L.; SOCCOL, A.T.; PANDEY, A.; VANDENBERGHE, L.P.S.; SOCCOL, C.R. Effect of caffeine and tannins on cultivatons and frutification of Pleurotus on coffee husks. Brazilian Journal of Microbiology, São Paulo, v.37, p.420-424, 2006.

HERNÁNDEZ, M.A.; DÍAZ, L.H. KlamiC ${ }^{\circledR}$ : bionematicida agrícola producido a partir del hongo Pochonia chlamydosporia var. Catenulata. Revista de Protección Vegetal, v.23, n.2, p.131-134, 2008.

KERRY, B.R.; BOURNE, J.M. A manual for research on Verticillium chlamydosporium, a potencial biological control agent for root-knot nematodes. [S.l.]: IOBC; OILB; WPRS/SROP, 2002. 84p.

KERRY, B.R.; CRUMP, D.H.; MULLEN, L.A. Studies of the cereal cyst-nematode, Heterodera avenae under continuous cereals, 1975-1978. II. Fungal parasitism of nematode females and eggs. Annals of Applied Biology, Warwick, v.100, p.489-499, 1982.
LOPES, E.A.; FERRAZ, S.; FERREIRA, P.A.; FREITAS, L.G.; DHINGRA, O.D.; GARDIANO, C.G.; CARVALHO, S.L. Potencial de isolados de fungos nematófagos no controle de Meloidogyne javanica. Nematologia Brasileira, Piracicaba, v.31, n.2, p.78-84, 2007.

MARINO, R.H.; ABREU, L.D. de; MESQUITA, J.B.; RIBEIRO, G.T. Crescimento e cultivo de diferentes isolados de Pleurotus ostreatus (jacq.: fr.) kummer em serragem da casca de coco. Arquivos do Instituto Biológico, São Paulo, v.75, n.1, p.29-36, 2008.

NOGUERA, P.; ABAD, M.; NOGUERA, V.; PURCHADES R.; MAQUIERA, A. Coconut coir waste, a new and viable ecologically-friendly peat substitute. Acta Horticulturae, The Hague, v.517, p.279-286, 2000.

PANDEY, A.; SOCCOL, C.R.; NIGAM, P.; BRAND, D.; MOHAN, R.; ROUSSOS, S. Biotechnological potential of coffee husk for bioprocesses. Biochemical Engineering Journal, Amsterdam, v.6, p.153-162, 2000.

PÉREZ-RODRÍGUEZ, I.; DOROTEO-MENDONZA, A.; FRANCO-NAVARRO, F.; SANTIAGO-SANTIAGO, V.; MONTERO-PINEDA, A. Isolates of Pochonia chlamydosporia var. chlamydosporia from Mexico as potential biological control agents of Nacobbus aberrans. Nematropica, Bradenton, v.37, n.1, p.127-134, 2007.

STIRLING, G.R.; LICASTRO, K.A.; WEST, L.M.; SMITH, L.J. Development of commercially acceptable formulations of the nematophagous fungus Verticillium chlamydosporium. Biological Control, Orlando, v.1, p.217-223, 1998. 